\title{
Michael D. Larrañaga, Richard J. Lewis and Robert A. Lewis (Eds.): Hawley's Condensed Chemical Dictionary. 16th Edn.
}

\author{
Edward R. Adlard ${ }^{1}$
}

Published online: 11 May 2017

(C) Springer-Verlag Berlin Heidelberg 2017

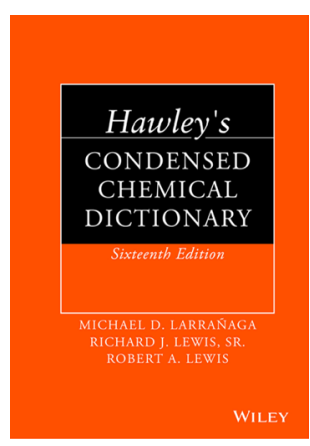

Bibliography

Hawley's Condensed Chemical

Dictionary, 16th Edn.

Michael D. Larrañaga, Richard J. Lewis,

Robert A. Lewis (Eds.)

John Wiley, Hoboken, NJ, USA, 2016,

pp xiii +1547

ISBN 978-1-11813515-0

GBP 120.00 , EUR 144.00

Having been involved in the production of a scientific reference work in the past, I imagine that the editors heaved a sigh of relief when this book was published. At nearly $2.3 \mathrm{~kg}$, it is a major production, although the "daddy" of such works must be the CRC Handbook of Chemistry and Physics (my 10-year-old edition of this weighs at staggering! $4 \mathrm{~kg})$.

The book starts with a three page introduction explaining various points concerning this and earlier editions, followed by a page of abbreviations used. I found this list useful, because many people seem to think that an abbreviation commonly used in their own work is common knowledge, which it may not be. The book ends with five appendixes which contain information on various topics from the origin of some chemical terms to tables of the elements.

The main body of the book lies between these two extremes, and because it is a dictionary, it has a built-in index, which makes it extremely easy to use. For example, I was able to find "perovskite" (a calcium/titanium mineral) without difficulty. This may well also be in the Handbook of Chemistry and Physics, but I would not know where to start looking in the latter.

There are those who seem welded permanently to their phone/tablet, and in these days of electronic devices, it could be argued that a work of the present sort is no longer necessary, but as one brought up in the quill pen era (nearly), I must admit to a preference for hard copy. There is also the point that in looking up one topic, one invariably comes across other useful and interesting information (examples of serendipity). One might also apply the words of Donald Rumsfeld to such circumstance, "there are things that we don't know that we don't know".

Overall, I think that this book is one that all chemists should have on their bookshelves as a valuable userfriendly reference work.
Edward R. Adlard

e.adlard77@btinternet.com

1 South Wirral, UK 